\title{
Humic Acid Degradation by ZnO Photocatalyst
}

\author{
Putri A. Sekartaji and Sandhya Babel \\ School of Biochemical Engineering and Technology, Sirindhorn International Institute of Technology (SIIT), Thammasat University, Thailand
}

\begin{abstract}
Humic acid (HA) is universally present in soils and natural water resources in a yellow-brown form. HA can react with chlorine during drinking water treatment and produce disinfection byproducts (DBPs), such as trihalomethanes (THMs) and haloacetic acids (HAAs), which are harmful for health. Therefore, HA has to be eliminated from water environment. The photocatalysis is an effective alternative solution for the degradation of HA in a water environment. This research aims to degrade HA from water environment. The rapid degradation of HA, using zinc oxide nanoparticles, irradiated by ultraviolet light $(\mathrm{ZnO} / \mathrm{UV})$, is investigated. The optimum conditions of pertinent factors, which include the light wavelength (UV-A and UV-C), and light intensity, HA concentration, $\mathrm{ZnO}$ dose, and contact time are investigated at neutral $\mathrm{pH}$ conditions, considered for drinking water treatment. HA degradation efficiency reached more than $80 \%$ after $60 \mathrm{~min}$ for both types of irradiation in optimum conditions of 0.3 $\mathrm{g} / \mathrm{L} \mathrm{ZnO}$ dose in 180 min of contact time. Comparisons for degradation efficiency under UV-A and UV-C irradiation indicate that UV-C has higher efficiency, up to $150 \mathrm{~min}$ of contact time. The reusability of catalyst is performed for three reuses and still revealed effective for beneficial commercial applications.
\end{abstract}

\section{Introduction}

Humic acid (HA) commonly exist in surface and ground water. Chemical structure is complex and contributes to natural organic matter (NOM). HA sources are from animal and plant materials break down. This can affect drinking water quality. HA can react with chlorine during drinking water treatment and produce disinfection byproducts (DBPs), such as trihalomethanes (THMs) and haloacetic acids (HAAs), which can cause potential health impacts [1], [2]. Hepplewhite et al reported that $\mathrm{HA}$ is present in drinking water at concentration levels of between 2 and $15 \mathrm{mg} / 1$ [3].

Recently, $\mathrm{ZnO}$ is used as an effective photocatalyst for organic pollutants degradation, due to its high photochemical reactivity, low cost and nontoxic [4]. $\mathrm{ZnO}$ showed a good performance in promoting generation of reactive oxygen species (ROS) under irradiation with energy [5]. Oskoei et al. studied HA degradation at lower initial concentrations under UV mercury lamp up to 60 minutes of contact timeusing $\mathrm{ZnO}$ [6]. Kim et al. analysed for higher initial concentrations of HA, using UV-C/NZLC [7]. However, behavior of HA degradation under higher range of contact time and under different intensities of UV-A and UV-C lamps are not comparatively investigated.

Thus, in this study, the potential of applying $\mathrm{ZnO}$ as catalyst in photocatalytic process to degrade HA from water environment under UV-A and UV-C is evaluated. Effect of pertinent factors affecting degradation are also evaluated.

\section{Materials and methods}

\subsection{Preparation of synthetic HA solution}

HA was obtained from Sigma-Aldrich. A stock solution of HA was prepared by using laboratory-grade humic acid-sodium salt solution. HA concentration of $5,8,11$ and $14 \mathrm{mg} / \mathrm{L}$ were prepared from stock solution using serial dilution with deionized water. A calibration curve was plotted using standardized HA solutions.

\section{2 $\mathrm{ZnO}$ as catalyst}

Zinc Oxide nanoparticle with a size of 6-12 nm, hexagonal crystal structure, $99.8 \%$ purity, was used. Since $\mathrm{ZnO}$ nanoparticles are more difficult to disperse in organic solvent, ultrasonication for 5-10 $\mathrm{min}$ is required for dispersion in solution.

\subsection{Experimental set up}

Experimental setup is shown in Fig. 1. Photocatalytic degradations were performed in sealed conditions. The whole system was covered by aluminium foil. One lamp was installed at the top of the reactor and two lamps on each side of the container. Two reactors each for UV-A (315-400 nm) and UV-C (100-280 nm) lamps, were used. During the experiment, the HA solution was mixed by using a magnetic stirrer.

\subsection{Methodology}

Photocatalytic experiment was done in a Pyrex beaker placed on the top of magnetic stirrer containing $100 \mathrm{ml}$ of 
HA solution at the concentration of 5, 8, 11 and $14 \mathrm{mg} / \mathrm{L}$. The $\mathrm{ZnO}$ doses were added at range $0.1-1 \mathrm{~g} / \mathrm{L}$. The suspensions were irradiated for various contact time ranging from $30-180 \mathrm{~min}$ in interval of $30 \mathrm{~min}$. After irradiation, the suspensions were filtered using $0.45 \mu \mathrm{m}$ syringe filters. HA concentrations was analyzed by using UV-visible spectrophotometer Thermo Scientific, Genesys at $276 \mathrm{~nm}$ wavelength. Effect of light intensity was investigated by varying the number of $8 \mathrm{~W}$ UV-A lamps i.e. $0.131 \mathrm{mw} / \mathrm{cm}^{2}, 0.167 \mathrm{mw} / \mathrm{cm}^{2}$ and 0.236 $\mathrm{mw} / \mathrm{cm}^{2}$, respectively, and $8 \mathrm{~W}$ UV-C lamps 0.196 $\mathrm{mw} / \mathrm{cm}^{2}, 0.233 \mathrm{mw} / \mathrm{cm}^{2}$ and $0.284 \mathrm{mw} / \mathrm{cm}^{2}$, respectively. Light intensity was measured at liquid surface. All experiments were performed at room temperature $(25 \pm$ $3^{\circ} \mathrm{C}$ ) and at neutral $\mathrm{pH}$ conditions. The reusability experiment of $\mathrm{ZnO}$ as a catalyst was done by centrifuging the sample for $20 \mathrm{~min}$ at $5000 \mathrm{rpm}$. It is followed by drying the catalyst at $60^{\circ} \mathrm{C}$ for at least $12 \mathrm{~h}$.

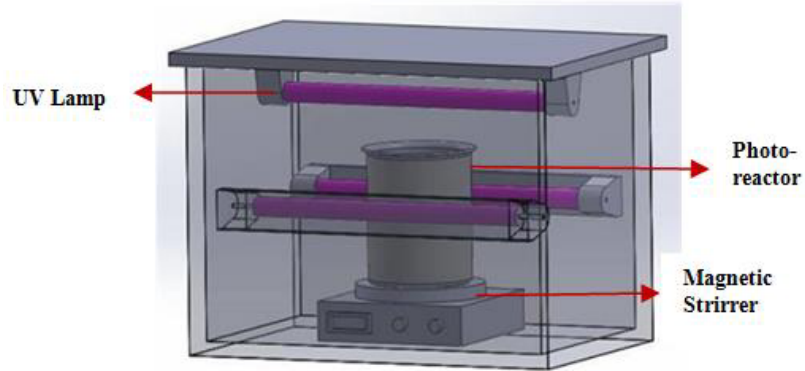

Figure 1. Schematic of the photocatalytic reactor

This experiment was done for UV-A and UV-C at light intensity $0.236 \mathrm{mw} / \mathrm{cm}^{2}$ and $0.284 \mathrm{mw} / \mathrm{cm}^{2}$, respectively, at optimum condition $(14 \mathrm{mg} / \mathrm{L}$ of $\mathrm{HA}, \mathrm{ZnO}$ dose $0.3 \mathrm{~g} / \mathrm{L}$, contact time $180 \mathrm{~min}$ ).

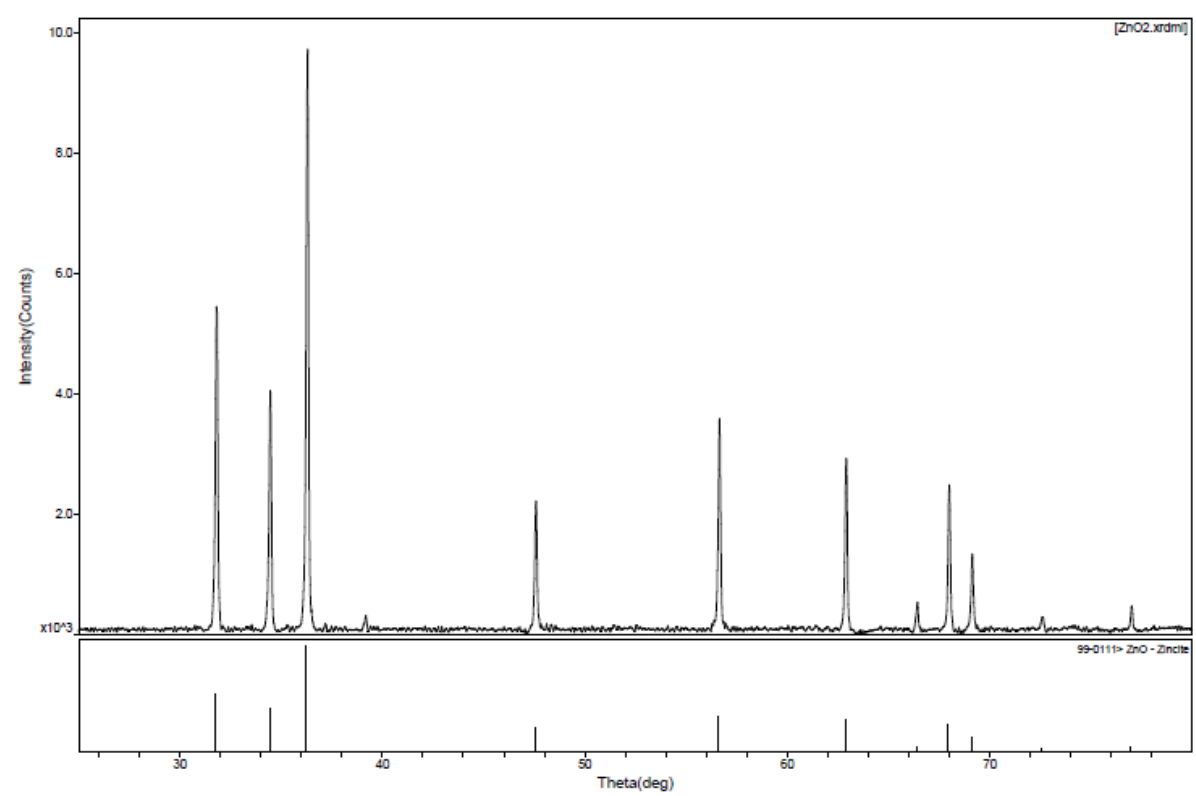

Figure 2. $\mathrm{X}$-ray diffraction pattern of $\mathrm{ZnO}$

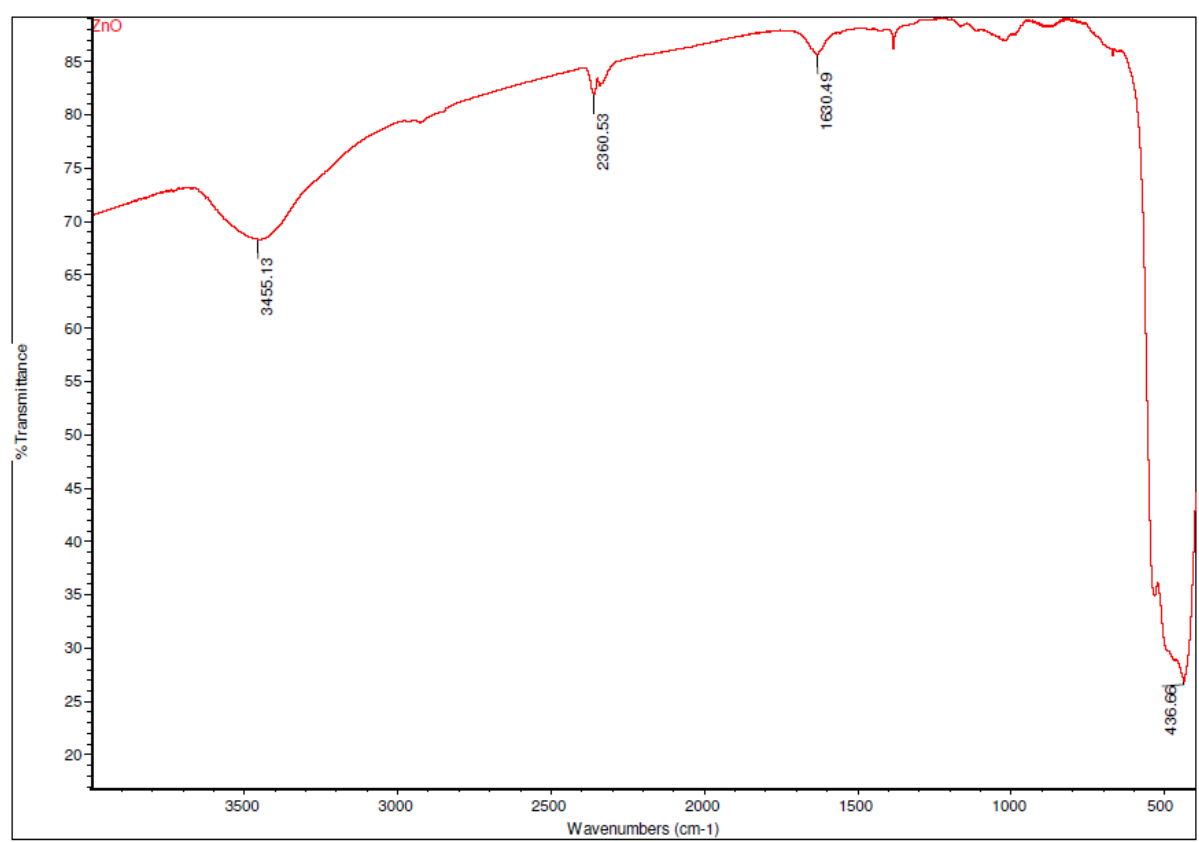

Figure 3. FT-IR spectra of $\mathrm{ZnO}$ 


\section{Results and discussions}

\subsection{ZnO characterization}

From XRD pattern of $\mathrm{ZnO}$ in Fig. 2, the facets ( $2 \mathrm{~h}$ value) at $31.7,34.3,36.3,47.6$ and 56.7 were assigned to (100), (002), (101), (102) and (110) reflection lines of hexagonal $\mathrm{ZnO}$, respectively. It indicates that the characteristic peaks represent the $\mathrm{ZnO}$ with hexagonal phase [8].

FT-IR spectra of the $\mathrm{ZnO}$ nanoparticles in Fig. 3 showed the fundamental mode of vibration at 3000-3600 $\mathrm{m}^{-1}$ which corresponds to the $\mathrm{O}-\mathrm{H}$ stretching vibration, $2360.53 \mathrm{~m}^{-1}$ which corresponds to $\mathrm{C}-\mathrm{H}$ stretching vibration and $1365 \mathrm{~m}^{-1}$ corresponds to $\mathrm{C}=\mathrm{O}$ asymmetric $\mathrm{C}=\mathrm{O}$ stretching vibration, $1630.49 \mathrm{~m}^{-1}$ corresponds to $\mathrm{C}=\mathrm{O}$ symmetric stretching vibration. $\mathrm{O}-\mathrm{H}$ bending of the hydroxyl group at $436.66 \mathrm{~m}^{-1}$ is observed [8].

\subsection{Effect of HA concentration}

The effect of HA concentration of was carried out at 0.1 $\mathrm{g} / \mathrm{L} \mathrm{ZnO}$ dose, for $60 \mathrm{~min}$. HA concentrations was varied from 5 to $14 \mathrm{mg} / \mathrm{L}$. From Fig. 4, it can be seen that increasing the initial concentration of HA decreases the degradation efficiency. The efficiency of HA degradation varied from $95 \%$ to $51 \%$ for UV-A and $97 \%$ to $47 \%$ for UV-C, respectively.

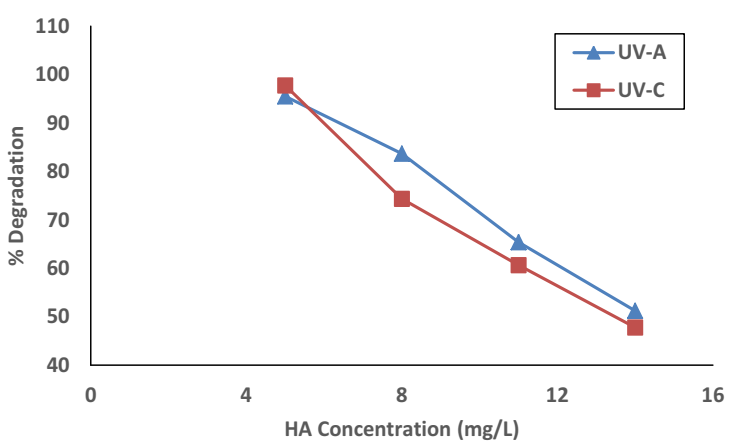

Figure 4. Effect of HA concentration on degradation by $\mathrm{ZnO}$ photocatalyst ( $\mathrm{ZnO}$ dose $0.1 \mathrm{~g} / \mathrm{L}$, contact time $60 \mathrm{~min}$ )

HA degradation decreased as the initial concentration increases and repulsive forces between molecules occurred, which effected in reduction in the number of hydroxyl radicals generated on the surface of catalyst by UV irradiations. Futhermore, a solution with a low concentration of HA with the same amount of hydroxyl radicals will have a higher degradation rate than a solution with a high concentration [9-11]. Previous studies on trichloroethylene (TCE) reported that the reaction by-products generated during the photocatalytic reaction can also decrease the degradation rate [11].

\subsection{Effect of $\mathrm{ZnO}$ dose}

In order to avoid the use of excess catalyst, it is necessary to find out the optimum loading for efficient removal of pollutant. Fig. 5 shows that increasing the $\mathrm{ZnO}$ dose from
0.1 to $1 \mathrm{~g} / \mathrm{L}$ increased degradation of $\mathrm{HA}$ from $51 \%$ to $94 \%$ for UV-A and $48 \%$ to $94 \%$ for UV-C, respectively, with a contact time of $60 \mathrm{~min}$. This is due to an increase in the active sites available for absorption of UV irradiations and adsorption of pollutant molecules which effects in producing large amounts of hydroxyl radicals. The result showed that rapid increase of HA degradation up to $0.5 \mathrm{~g} / \mathrm{L} \mathrm{ZnO}$ dose. The increase subsequent to 0.5 $\mathrm{g} / \mathrm{L}$ seemed gradual.

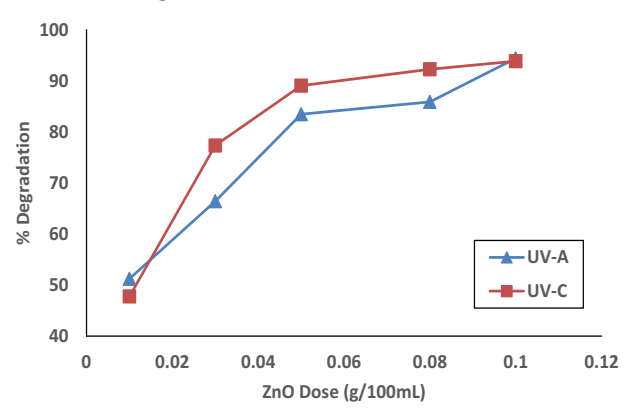

Figure 5. Effect of $\mathrm{ZnO}$ dose on degradation of HA (HA conc. $5 \mathrm{mg} / \mathrm{L}$, contact time $60 \mathrm{~min}$ )

\subsection{Effect of contact time}

From the $\mathrm{ZnO}$ dose results, $0.5 \mathrm{~g} / \mathrm{L}$ seemed to be the optimum dose. However, experiments were done for both $0.3 \mathrm{~g} / \mathrm{L}$ and $0.5 \mathrm{~g} / \mathrm{L}$. It was observed that significant results for $60 \mathrm{~min}$ of contact time, could be obtained from $0.3 \mathrm{~g} / \mathrm{L}$. Therefore, $0.3 \mathrm{~g} / \mathrm{L}$ was selected as the optimum of $\mathrm{ZnO}$ dose. For experiments conducted here onwards.

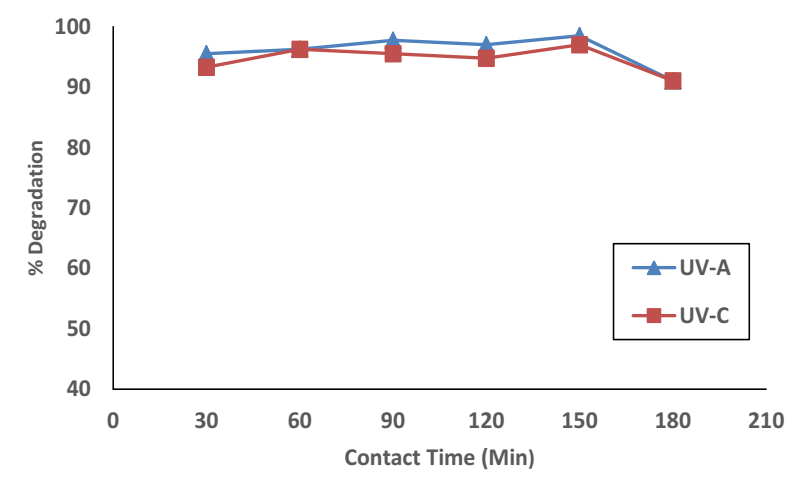

Figure 6(a). Effect of contact time on degradation of HA by $\mathrm{ZnO}$ photocatalyst (HA conc. $5 \mathrm{mg} / \mathrm{L}, \mathrm{ZnO}$ dose $0.3 \mathrm{~g} / \mathrm{L}$ )

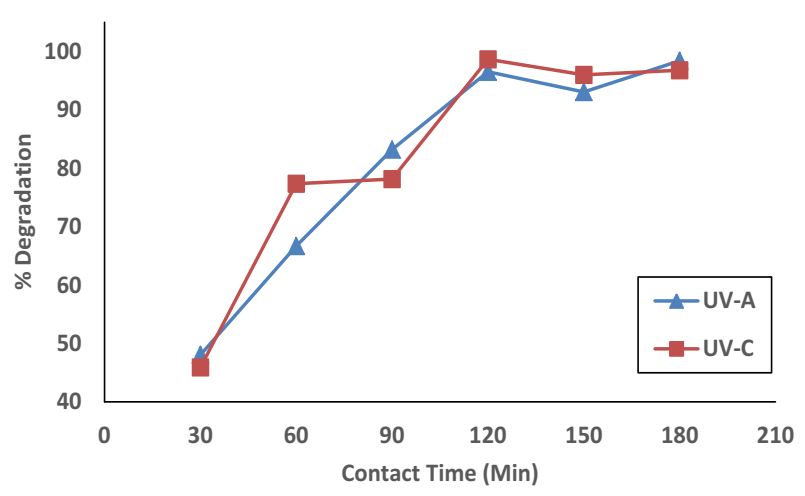

Figure 6(b). Effect of contact time on degradation of HA by $\mathrm{ZnO}$ photocatalyst (HA conc. $14 \mathrm{mg} / \mathrm{L}, \mathrm{ZnO}$ dose $0.3 \mathrm{~g} / \mathrm{L}$ ) 
Fig. 6(a) and (b) show the effect of contact time for HA concentration of $5 \mathrm{mg} / \mathrm{L}$ and $14 \mathrm{mg} / \mathrm{L}$, respectively . It shows that increasing the contact time from $30 \mathrm{~min}$ to $180 \mathrm{~min}$ increased degradation efficiency. The result has shown insignificant variation of degradation efficiency for lower concentration at $5 \mathrm{mg} / \mathrm{L}$, with time. The $\mathrm{ZnO}$ dissolution might have occurred due to this condition. The results show rapid increase of degradation efficiency for higher concentration at $14 \mathrm{mg} / \mathrm{L}$, especially at low contact time. After $120 \mathrm{~min}$ of contact time, degradation efficiency remained nearly constant in this condition. The degradation efficiency was rapid at the beginning because there were a large number of active sites available on the surface of the adsorbent. The number of sites decreased over time with the gradual occupation of sites by HA. This results in increasing repulsive forces between the adsorbed molecules leading to decreased degradation [6].

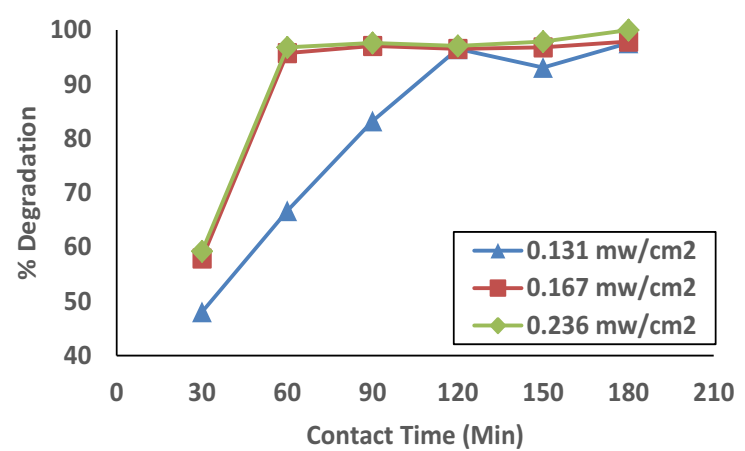

Figure 7(a). Effect of light intensity (UV-A) on degradation of $\mathrm{HA}$ by $\mathrm{ZnO}$ photocatalyst (HA conc. $14 \mathrm{mg} / \mathrm{L}, \mathrm{ZnO}$ dose 0.3 $\mathrm{g} / \mathrm{L}$, contact time from $30-180 \mathrm{~min}$ )

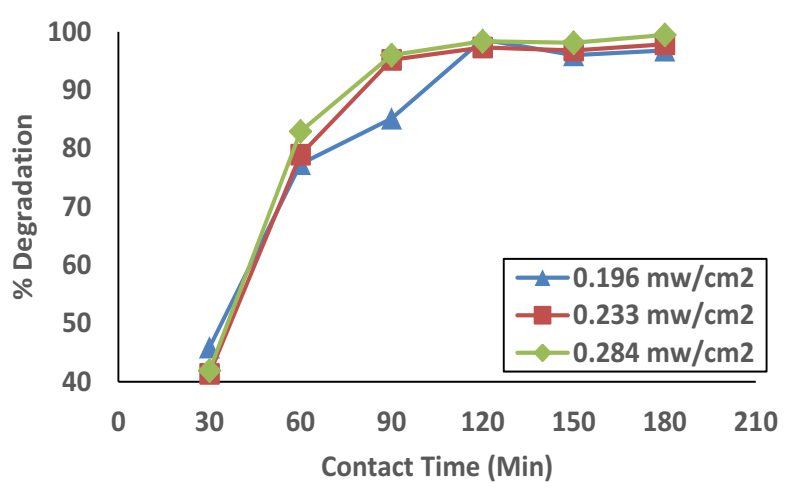

Figure 7(b). Effect of light intensity (UV-C) on degradation of $\mathrm{HA}$ by $\mathrm{ZnO}$ photocatalyst (HA conc. $14 \mathrm{mg} / \mathrm{L}, \mathrm{ZnO}$ dose 0.3 $\mathrm{g} / \mathrm{L}$, contact time from $30-180 \mathrm{~min}$ )

\subsection{Effect of light intensity}

Fig. 7(a) and Fig. 7(b) show the effects of light intensity of $14 \mathrm{mg} / \mathrm{L}$ HA concentration for UV-A and UV-C, respectively, with time. In this study, contact time is varied from 30-180 min when finding the effect of light intensity. Fig. 7(a) shows that under UV-A irradiation, different behaviours are observed in different light intensities. The lower intensity required $120 \mathrm{~min}$ of contact time to reach more than $90 \%$ of HA degradation. On the other hand, higher intensities required only $60 \mathrm{~min}$ of contact time. Fig 7(b) shows lower intensity of UV-C irradiation required $120 \mathrm{~min}$ to reach more than $90 \%$ of HA degradation. For higher intensities required $90 \mathrm{~min}$ of contact time. These graphs indicate that in terms of contact time, UV-A required lower contact time than UV$\mathrm{C}$ to reach $90 \%$ of HA degradation. However, UV-C seemed to have higher degradation efficiency up to 150 min. Similar observation was obtained in a previous study by Bak et al, in an experiment done for trichloroethylene [11]. Higher intensity conditions will lead to higher electron-hole pair generation rate. Therefore, higher degradation efficiency is obtained, due to higher photocatalytic activity [12].

Fig. 8 indicates that more than $50 \%$ of HA degradation is dominated by photodegradation. The activity of $\mathrm{ZnO}$ showed better degradation of HA under irradiation condition. Due to that result, the photodegradation using $\mathrm{ZnO}$ provides higher concentration of hydroxyl ions to react with holes to form hydroxyl radicals. Hydroxyl radical is considered to be responsible for oxidation decomposition of organic compound. However, agglomeration and accumulation of $\mathrm{ZnO}$ might be occurred in the absence of irradiation.

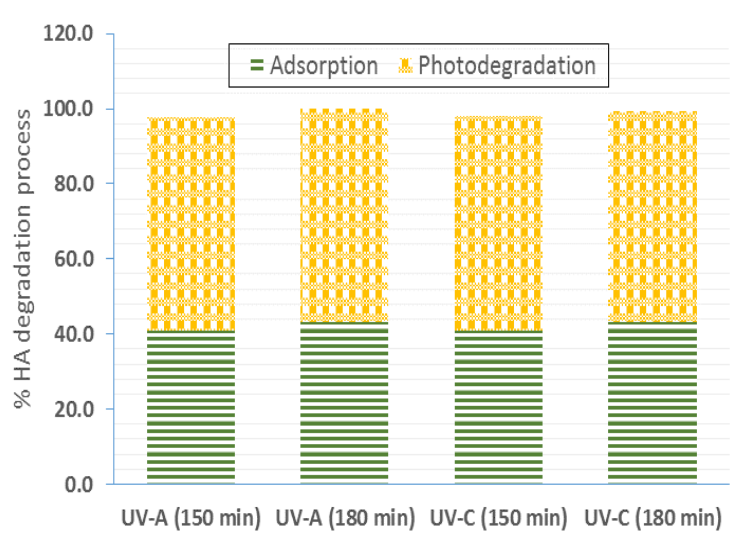

Figure 8. The ratio of adsorption and photodegradation to total of HA degradation percentage.

\subsection{Reusability of Catalyst}

In order to study the reusability of the catalyst, centrifugation separation method was used. Photocatalytic experiments were performed at $14 \mathrm{mg} / \mathrm{L}$ $\mathrm{HA}$ and $0.3 \mathrm{~g} / \mathrm{L} \mathrm{ZnO}$, with $180 \mathrm{~min}$ of contact time. The $\mathrm{ZnO}$ was reused up to three cycles with consistent activity. Similar studies were done on $\mathrm{TiO}_{2}$ for five cycles [13]. After three cycles of reusability, the percentages of degradation obtained were $88 \%$ for UV-A and $76 \%$ for UV-C, respectively. With higher number of cycles, the percentage of catalyst recovery decreased. The decrease of HA degradation might occur from the photocorrosion effect, which affected catalyst to a large extent. L.Huang et al, showed similar result on $\mathrm{Cu}_{2} \mathrm{O}$ where the photocorrosion rate was rapid in catalyst as against their micron sized counterparts [14]. Therefore, three cycles of reusability is suggested to be acceptable from the experiments of this study.

\section{Conclusions}

In this study, HA degradation by $\mathrm{ZnO}$ photocatalyst was carried out. The photocatalytic degradation of HA was 
studied by varying parameters that can be used to degrade $\mathrm{HA}$ in drinking water. Increasing the initial concentration of HA decreases the degradation efficiency due to the reduction of generated hydroxyl radicals. As the $\mathrm{ZnO}$ dose increases, degradation efficiency increases. HA degradation under high intensity UV-A irradiation required lower contact time, to reach $90 \%$ degradation. HA degradation efficiency under UV-C has higher efficiency, up to $150 \mathrm{~min}$ of contact time. The reusability of $\mathrm{ZnO}$ was demonstrated with consistent activity, and is still effective at three cycles. The use of catalyst creates a technical problem in retrieving the catalyst from the treated water. The authors suggest an immobilized catalyst for commercial applications for future works. Moreover, using the results of this study, efficiencies of different photocatalysts are to be comparatively investigated to remove HA from drinking water.

\section{Acknowledgment}

This research was supported by Sirindhorn International Institute of Technology, Thammasat University and The Asian Development Bank.

\section{References}

1. De Wuilloud J.C, Sadi B.B. and Caruso J.A., "Trace humic and fulvic acid determination in natural water by cloud point extraction/pre-concentration using non-ionic and cationic surfactants with FI-UV detection". The Analyst 128, 453-458, (2003).

2. Liu S, Lim M, Fabris R, Chow C, Drikas M, and Amal R., " $\mathrm{TiO}_{2}$ Photocatalysis of Natural Organic Matter in Surface Water: Impact on Trihalomethane and Haloacetic Acid Formation Potential" in Environ. Sci. Technol. 42: 6, pp. 218-223, (2008).

3. Hepplewhite C, Newcombe G and Knappe D, "NOM and MIB, who wins in the competition for activated carbon adsorption sites?" in Water Sci. Technol. 49, pp. 257-267, (2004).

4. Hongbo Ma, Phillip L. Williams, Stephen A. Diamond, Ecotoxicity of manufactured $\mathrm{ZnO}$ nanoparticles - a review, Environ. Pollut. 172: 76-85, (2013)
5. Ravichandrika, K., Kiranmayi, P. \& Ravikumar, "Synthesis, characterization and antibacterial activity of $\mathrm{ZnO}$ nanoparticles", International Journal of pharmacy and pharmaceutical Science, 4, ISSN0975-1491, p. 336-338, (2012).

6. V. Oskoei, M.H. Dehghani, S. Nazmara, B. Heibati, M. Asif, I. Tyagi, Shilpi Agarwal and Vinod Kumar Gupta, "Removal of humic acid from aqueous solution using $\mathrm{UV} / \mathrm{ZnO}$ nano-photocatalysis and adsorption", Journal of Molecular Liquids 213: 374380, (2016).

7. Kim, J.K,. Alajmy, J., Borges, A.C., Joo, J.C., Anh, H., and Campos, L.C, "Degradation of Humic Acid by Photocatalytic Reaction Using Nano-sized ZnO/Laponite Composite", Water Air Soil Pollut. 224:1749, (2013).

8. G.E. Fryxell, and G. Cao, "Environmental Applications of Nanomaterials: Synthesis, Sorbents and Sensors", World Scientific, (2007).

9. M. A. Behnajady, N. Modirshahla, and R. Hamzavi, "Kinetic study on photocatalytic degradation of C.I. acid yellow 23 by $\mathrm{ZnO}$ photocatalyst," Journal of Hazardous Materials, 133, no.1-3, pp. 226-232, (2006).

10. H. Yang, G. Li, T. An, Y. Gao, and J.Fu, "Photocatalytic degradation kinetics and mechanism of environmental pharmaceuticals in aqueous suspension of $\mathrm{TiO}_{2}$ : a case of sulfa drugs," Catalysis Today, 153, no. 3-4, pp. 200-207, (2010).

11. Bak S, Song M, Nam I, Lee WG, "Photocatalytic Oxidation of Trichloroethylene in Water Using a Porous Ball of Nano-ZnO and Nanoclay Composite", Journal of Nanomaterials, Article ID 160212, 8 pages, (2015).

12. G.E. Fryxell, G. Cao, Environmental Applications of Nanomaterials: Synthesis, Sorbents and Sensors, World Scientific, (2007).

13. Sekartaji, Putri Ardyarini and Sandhya Babel. Degradation of humic acid by using $\mathrm{TiO}_{2}$ photocatalyst. In Proceedings of the 10th GMSARN International Conference 2015 on Smart Energy, Environment and Community Development in GMS, (2015).

14. L.Huang, F.Peng, H.Yu and H.Wang, Solid State Sci. 11: 129-138, (2009). 